\title{
Aspects of the breeding biology of the southern rockhopper penguin Eudyptes c. chrysocome and new consideration on the intrinsic capacity of the A-egg
}

\author{
Maud Poisbleau • Laurent Demongin · Ian J. Strange • \\ Helen Otley · Petra Quillfeldt
}

Received: 10 October 2007 / Revised: 9 February 2008 / Accepted: 13 February 2008 / Published online: 11 March 2008

(C) The Author(s) 2008

\begin{abstract}
The rockhopper penguins Eudyptes chrysocome have recently been split into the northern E. moseleyi and the southern E. chrysocome rockhopper penguin. It is therefore crucial to have a comprehensive understanding of the biology of each species in order to develop appropriate conservation measures. We investigated the breeding biology of the southern rockhopper on New Island, in the western part of the Falklands Islands, by following the breeding attempt of 160 pairs during the 2006/2007 season and examining the effect of lay time and colony habitat on breeding success. Specifically, we compared survival and growth parameters between A- and B-eggs and chicks from non-manipulated and artificially manipulated nests to investigate why southern rockhopper penguins in the Falkland Islands are more able to fledge an A-egg (first laid) than conspecifics elsewhere. Breeding was highly synchronous, with no significant difference in the breeding success between early and late breeders or between pairs breeding in different habitats. We demonstrate for the first time that the A-egg produced by the southern rockhopper penguin has, when alone, the same theoretical intrinsic potential to
\end{abstract}

M. Poisbleau ( $\varangle) \cdot$ L. Demongin · P. Quillfeldt

Max Planck Institute for Ornithology,

Vogelwarte Radolfzell, Schlossallee 2,

78315 Radolfzell, Germany

e-mail: poisbleau@orn.mpg.de

\section{J. Strange}

New Island Conservation Trust,

New Island, FIQQ 1ZZ, Falkland Islands

H. Otley

Environmental Planning Department,

Falkland Islands Government,

Stanley FIQQ 1ZZ, Falkland Islands lead to a fledged chick as the B-egg. In contrast, the hatching success and survival of the B-chick was similar when alone or in a two-egg clutch.

Keywords Southern rockhopper penguin .

Breeding biology $\cdot$ Falkland Islands $\cdot$ Egg dimorphism .

Chick survival · Growth curves

\section{Introduction}

Recent genetic analyses of the genus Eudyptes have suggested that there are two or even three separate species of the rockhopper penguin Eudyptes chrysocome (Banks et al. 2006; Jouventin et al. 2006). In 2007, BirdLife International formally separated the southern rockhopper $E$. chrysocome from the northern rockhopper E. moseleyi. With this reclassification, the conservation statuses of the two new species are likely to be graded by the IUCN as endangered for the northern rockhopper penguin and vulnerable for the southern rockhopper penguin (BirdLife International Threatened Seabirds Forum).

Despite an apparently high level of breeding success in the Falkland Islands, the southern rockhopper penguin population is in severe decline. During the 1930s, the Falkland Islands was considered to hold one of the largest populations of the species at 1,800,000 breeding pairs, but currently the total population is 210,000 breeding pairs (Pütz et al. 2003a; Huin 2007). For the last two decades, population, diet, foraging range and colony breeding success have been investigated at a number of sites across the Falkland Islands (e.g. Strange 1982; Lamey 1993; St. Clair 1996; Pütz et al. 2001, 2002, 2003b, 2006; Clausen and Pütz 2002; Boersma et al. 2002; Huin 2005). However, its general breeding biology in the Falkland Islands has not been 
studied in any detail and/or over multiple years and yet it is critical to have a comprehensive understanding of the biology of the species in order to develop appropriate conservation measures.

The general breeding biology of the rockhopper penguin has been described at many breeding sites across its geographic range. In spring months, rockhopper penguins return to colony areas and some weeks later, a first egg (A-egg) is laid, with the $30 \%$ larger second egg (B-egg) arriving four days later (Warham 1975; Williams 1995). Both parents share the 32-34 day long incubation, with the male and female present for the first shift of 12 days, the female undertaking the second 11-day shift and the male returning to the nest for the final shift of 14 days. Commonly both eggs hatch, the B-egg usually first, and the A-chick generally dies of starvation within days after hatching (Gwynn 1953; Lamey 1990). The male then guards the B-chick for 24-26 days with the female returning with food nearly every day, after which the chick waits in a crèche to be provisioned by both males and females (Williams 1995).

However, the reported pattern and breeding success do appear to differ somewhat between species and localities. Whilst southern rockhopper penguins breeding in the Indian Ocean and Pacific Ocean almost never rear two chicks (Warham 1975; Williams 1980a, 1995; Marchant and Higgins 1990; Hull et al. 2004), there is evidence that suggests that it is not unusual for southern rockhopper penguin pairs in the Falkland Islands to raise two chicks (Strange 1982; Pütz et al. 2001; Clausen and Pütz 2002). Strange (1982) first described the general breeding biology of this species at New Island, in the western part of the Falklands Islands and both he and subsequently Lamey (1993) in the same breeding site found that more than $80 \%$ of all pairs retained both eggs until at least one hatched successfully but that most of the A-eggs or just hatched A-chicks were lost during the hatching period.

The role of the A-egg in the reproductive effort of the rockhopper penguin has been studied at a number of sites in the context of obligate brood reduction (see St. Clair 1998). It is suggested that the A-egg may produce a chick, but that the hatching asynchrony and sibling competition between both siblings generally prevents the latter and smaller egg/ chick to survive (Lamey 1990, 1993; St. Clair 1996; St. Clair and St. Clair 1996). Our study set out to test this hypothesis and to qualify the intrinsic capacity of the A-egg to fledge chick.

The primary aim of our study was to provide a detailed description of the timing and duration of laying, brooding and fledging periods, and the egg and chick growth parameters for the southern rockhopper penguin in the Falkland Islands. To examine the occurrence of two-chick broods within this population and the capacity of the A-egg, we artificially created broods with only an A- or a B-egg. In this context, we also examined the effect of breeding timing and colony habitat characteristics on reproductive success. The methodological design also included monitoring of non-manipulated pairs, in order to determine the effect of the research and researcher presence on the breeding success of the pairs studied.

\section{Methods}

Birds and study site

The study was carried out at the "Settlement Colony" on New Island, Falkland Islands $\left(51^{\circ} 43^{\prime} \mathrm{S}, 61^{\circ} 17^{\prime} \mathrm{W}\right)$ between October 2006 and February 2007. The colony has around 5,000 pairs of breeding southern rockhopper penguins. Within the main part of the Settlement Colony, we identified one sub-colony that was interspersed with and fringed by tussac grass Poa flabellata, which provided a semi-open habitat (entitled the S-colony) and a second sub-colony in an open rocky area without vegetation (entitled the O-colony). After the arrival of the first males back to the colony (first October), we visited the two sub-colonies daily in order to initially mark active nests and then subsequently to record and follow breeding success.

When each nest in the two sub-colonies had two eggs, it was randomly assigned to a treatment: A-nest, B-nest, $\mathrm{AB}$ nest and control-nest in the S-colony, and $\mathrm{AB}$-nest and control-nest in the O-colony. A- and B-nests were located in only S-colony because it had more breeding pairs and more nests that were accessible. We followed the breeding activities in 160 nests assigned to the five treatments (see Table 1). In the A- and B-nest treatments, in order to obtain an obligate A- or B-egg clutch, the day after the B-egg was laid, we removed one egg, with the A-nest having only the A-egg and the B-nest having only the B-egg.

\section{Egg and chick manipulations}

When a new egg was detected in a nest, we marked it with a unique code, measured its length and breadth to the nearest $0.1 \mathrm{~mm}$ with vernier callipers and weighed it to the nearest $0.1 \mathrm{~g}$ using a digital balance. We calculated egg density $\left(\mathrm{g} / \mathrm{cm}^{3}\right)$ at laying from the equation of laying mass $(\mathrm{g}) /\left[\right.$ length $\quad(\mathrm{cm}) \times$ breadth $\left.\quad(\mathrm{cm})^{2} \times 0.512\right], \quad$ following Stonehouse (1966).

When a newly hatched chick was detected in an experimental nest (A-, B- or AB-nest), it was immediately measured and weighed, and then re-measured on average every six days. We weighed chicks with a body mass less than $300 \mathrm{~g}$ to the nearest gram using a digital balance and heavier chicks were weighed to the nearest $10-20 \mathrm{~g}$ using 
Table 1 Lay dates for A-eggs of early- and late-nests and numbers of nests assigned to each of the four treatments in the S- and O-colonies

\begin{tabular}{lrr}
\hline & Early-nests & Late-nests \\
\hline S-colony & & \\
A-egg lay dates & 27 Oct-31 Oct & 01 Nov-05 Nov \\
A-nests & 12 & 12 \\
B-nests & 10 & 12 \\
AB-nests & 12 & 12 \\
Control-nests & 15 & 15 \\
Subtotal & 49 & 51 \\
O-colony & & \\
A-egg lay dates & 30 Oct-02 Nov & 15 \\
AB-nests & 15 & 15 \\
Control-nests & 15 & 30 \\
Subtotal & 30 & 81 \\
Total & 79 & Nov-06 Nov \\
\hline A- & & 15 \\
\hline
\end{tabular}

A- and B-nests were located in S-colony because it had more breeding pairs and more accessible nests

an adapted spring balance. In order to minimise observer bias, one observer (LD) measured bill length (exposed culmen length) to the nearest $0.1 \mathrm{~mm}$ using a calliper and flipper length, extended from axilla, to the nearest $1.0 \mathrm{~mm}$ with a ruler (following Amat et al. 1993). An index of body condition was calculated as the ratio of body mass ( $\mathrm{g}$ ) to flipper length $(\mathrm{mm})$, such that high values represent chicks in good body condition (Robinson et al. 2005). The coefficient of the regression lines for body mass, bill length and flipper length of chicks measured on least three occasions and still alive at fledging age was used to describe daily growth rate (as $\mathrm{g} /$ day or $\mathrm{mm} /$ day).

Chicks in nests with siblings less than five days of age were marked on one nail with non-toxic paint marker and on the subsequent re-weighing, these chicks were individually marked with a numbered colour Velcro band on each flipper, as used by Hull et al. (2004). The bands were removed from chicks in February prior to their first departure to sea.

\section{Manipulation and visitation impacts}

To quantify the effect of the egg, chick and adult handling on breeding success, we monitored hatching success and the number of chicks that survived to the end of the brood period in the 60 control-nests within the S-and O-colonies. In control-nests, eggs were only handled soon after being laid to mark them and chicks were only handled at 18 days of age (two days before the average duration of the brood period at New Island, Strange 1982).

However, as the control-nests were located amongst manipulated nests, all nests in the sub-colonies were exposed to the daily visitation of two researchers. To quantify the effect of research presence in the sub-colonies on hatching success, we also counted the number of eggs and/ or chicks in an open and semi-open sub-colony adjacent to each study sub-colony. The two undisturbed sub-colonies (BS-nests) had similar numbers of nests to the O- and S-colonies (i.e. 65-70 nests). Counts of eggs/chicks were made at three crucial and identifiable days according to the breeding chronology in our study pairs: (1) the day when we observed less than two new A-eggs laid, (2) three days before the expected date of hatching and (3) the day after the last hatched egg.

\section{Statistical analysis}

We tested differences between treatments by general linear modelling (GLM) when the data was normally distributed and by the Mann-Whitney test for data with a different distribution. Differences in numbers of eggs and/or chicks with count date were examined with a two-way repeated ANCOVA, where date of count was included as a repeated measure. All statistical analyses were performed using SPSS 15.0. All values are presented as mean \pm SD, unless otherwise indicated.

\section{Results}

Egg measurements

Observed lay dates for A-eggs ranged between 27 October and 10 November, with less than $5 \%$ of new A-eggs found after 5 November. Because all these very few extremely late eggs were found either without parental attendance, outside of a properly made nest or in a peripheral location, we did not take account of them when presenting the following results.

A-eggs were laid significantly later in O-colony than in S-colony $(U=4031.0, P<0.001)$. For this reason, the dates used to classify nests as being early or late differed between the two colonies (see Table 1).

Within clutches, B-egg was laid a mean of $4.09 \pm$ 0.54 days $(N=160)$ after A-egg. This interval did not differ between early- and late-nests and between sub-colonies $(U=2889.0, P=0.179$ and $U=2937.0, P=0.778$, respectively). Comparing both eggs from A-, B- and AB-nests pooled together (i.e. all the experimental nests), we observed that B-eggs were larger and heavier than A-eggs at laying but that their initial densities were similar (Table 2). Within clutches, the B-egg was $28.0 \pm 7.4 \%$ larger and $28.4 \pm 7.0 \%$ heavier than the A-egg. Subsequently, there were no significant differences between early- and late-nests and between sub-colonies except that eggs in S-colony were slightly longer and less dense than eggs in O-colony (Table 2). 
Table 2 Summary statistics [mean \pm SD (range)] for A- and B-eggs at laying using both eggs from A-, B- and AB-nests

\begin{tabular}{|c|c|c|c|}
\hline & A-egg & B-egg & Difference \\
\hline Length (mm) & $65.65 \pm 2.61(59.6-71.2)$ & $70.57 \pm 2.26(66.1-75.6)$ & $\begin{array}{l}\text { Egg } F_{1,193}=204.158, P<0.001 \\
\text { Early/late } F_{1,193}=0.203, P=0.653 \\
\text { Sub-colony } F_{1,193}=4.923, P=0.028\end{array}$ \\
\hline Breadth $(\mathrm{mm})$ & $49.81 \pm 1.80(45.5-54.7)$ & $54.28 \pm 1.62(50.2-58.2)$ & $\begin{array}{l}\text { Egg } F_{1,193}=335.385, P<0.001 \\
\text { Early/late } F_{1,193}=0.695, P=0.405 \\
\text { Sub-colony } F_{1,193}=0.988, P=0.321\end{array}$ \\
\hline Volume $\left(\mathrm{cm}^{3}\right)$ & $83.62 \pm 8.19(70.16-104.63)$ & $106.62 \pm 8.44(87.34-130.76)$ & $\begin{array}{l}\text { Egg } F_{1,193}=379.227, P<0.001 \\
\text { Early/late } F_{1,193}=0.160, P=0.690 \\
\text { Sub-colony } F_{1,193}=2.802, P=0.096\end{array}$ \\
\hline Mass (g) & $90.74 \pm 8.79(76.6-115.3)$ & $116.19 \pm 9.42(92.8-144.7)$ & $\begin{array}{l}\text { Egg } F_{1,193}=384.846, P<0.001 \\
\text { Early/late } F_{1,193}=0.159, P=0.690 \\
\text { Sub-colony } F_{1,193}=1.762, P=0.186\end{array}$ \\
\hline Density $\left(\mathrm{g} / \mathrm{cm}^{3}\right)$ & $1.085 \pm 0.015(1.046-1.125)$ & $1.090 \pm 0.016(1.031-1.120)$ & $\begin{array}{l}\text { Egg } F_{1,193}=3.598, P=0.059 \\
\text { Early/late } F_{1,193}=0.009, P=0.925 \\
\text { Sub-colony } F_{1,193}=4.228, P=0.041\end{array}$ \\
\hline
\end{tabular}

Two eggs from the same nest with extreme and isolated length (A-egg $76.8 \mathrm{~mm}$, B-egg $78.8 \mathrm{~mm}$ ) were not used to calculate these means and one A-egg from an AB-nest was lost before it could be measured. A-eggs $N=98$ and B-eggs $N=99$. GLM with three factors were performed to identify differences between A- and B-eggs, between early- and late-nests and between sub-colonies (S- vs. O-colonies) in egg length (proportion of variation in the dependent variable explained by the three factors $\left.R^{2}=0.520\right)$, breadth $\left(R^{2}=0.636\right)$, egg volume $\left(R^{2}=0.664\right)$, laid egg mass $\left(R^{2}=0.667\right)$ and initial egg density $\left(R^{2}=0.039\right)$. None of the interactions between factors was significant

Hatching observations

Within non-manipulated study nests (i.e. AB-nests), the hatching success of each egg was not significantly different between A- and B-eggs, between early- and late-nests or between sub-colonies (Table 3a). The mean hatching success was $66 \%$ (71 hatched eggs). Within all the experimental nests (i.e. A-, B- and AB-nests pooled all together), the hatching success was not significantly affected by the presence of a sibling $(U=2579.0, P=0.645)$. Nevertheless, within $\mathrm{AB}$-nests, the incubation duration (counted from the lay date of the B-egg) was significantly shorter for B-eggs (mean of $32.10 \pm 1.02$ days, $N=39$ ), which hatched before A-eggs (mean of $33.19 \pm 1.31$ days, $N=32$, Table $3 \mathrm{a}$ ). The duration between the hatching of the A- and B-egg did not differ between early- and late-nests and between sub-colonies (Table 3a).

Within all the experimental nests, the incubation duration for A-eggs was affected by the presence of a sibling, with a mean incubation of $33.19 \pm 1.31$ days $(N=32)$ for

Table 3 Tests of the differences in (a) hatching and (b) growth parameters

\begin{tabular}{|c|c|c|c|}
\hline & A- vs. B-Chicks & Early- vs. late-nests & S- vs. O-colonies \\
\hline \multicolumn{4}{|c|}{ (a) Hatching parameters for non-manipulated brood (AB-nests) } \\
\hline Hatching success & $U=1269.0, P=0.158$ & $U=1593.0, P=0.313$ & $U=1362.0, P=0.557$ \\
\hline Incubation duration & $U=922.5, P<0.001$ & $U=680.5, P=0.518$ & $U=657.0, P=0.717$ \\
\hline Flipper length & $F_{1,53}=21.892, P<0.001$ & $F_{1,53}=1.674, P=0.201$ & $F_{1,53}=0.369, P=0.546$ \\
\hline Bill length & $F_{1,53}=8.720, P=0.005$ & $F_{1,53}=0.520, P=0.474$ & $F_{1,53}=4.524, P=0.038$ \\
\hline Mass & $F_{1,49}=69.211, P<0.001$ & $F_{1,49}=1.925, P=0.172$ & $F_{1,49}=0.246, P=0.622$ \\
\hline \multicolumn{4}{|c|}{ (b) Growth parameters for all the experimental nests (A-, B- and AB-nests) } \\
\hline Crèche age & $F_{1,62}=0.544, P=0.464$ & $F_{1,62}=0.031, P=0.861$ & $F_{1,62}=0.127, P=0.722$ \\
\hline Mass growth rate & $\mathrm{U}=471.0, \mathrm{P}=0.871$ & $\mathrm{U}=560.5, \mathrm{P}=0.995$ & $\mathrm{U}=434.0, \mathrm{P}=0.622$ \\
\hline Flipper growth rate & $U=447.5, P=0.631$ & $U=547.0, P=0.861$ & $U=430.0, P=0.584$ \\
\hline Bill growth rate & $U=465.0, P=0.807$ & $U=518.5, P=0.593$ & $U=450.0, P=0.784$ \\
\hline
\end{tabular}

GLM were performed to identify differences between A- and B-eggs, between early- and late-nests and between sub-colonies (S- vs. O-colonies) in flipper length (proportion of variation in the dependent variable explained by the model $R^{2}=0.312$ ), bill length $\left(R^{2}=0.206\right)$ and mass $\left(R^{2}=0.590\right)$ at hatching and in age at the end of the brood period (crèche age, $\left.R^{2}=0.015\right)$. None of the interactions was significant. Independent Mann-Whitney tests were performed to identify differences in other parameters 
A-eggs incubated with a sibling for a minimum of 30 days compared to $32.12 \pm 0.81$ days $(N=16)$ for A-eggs incubated without sibling for a minimum of 30 days $(U=133.0$, $P=0.005)$. However, this was not the case for B-eggs ( $U=234.0, P=0.120)$. Therefore, incubation duration of an A- and B-egg when incubated alone was not different ( $U=98.9, P=0.214)$.

Within $24 \mathrm{~h}$ after hatching, B-chicks from AB-nests were $36.8 \%$ heavier than A-chicks $(85.8 \pm 11.4 \mathrm{~g}, N=30$ and $62.7 \pm 7.9 \mathrm{~g}, N=23$, respectively, Table $3 \mathrm{a}$ ). The flipper and bill of B-chicks were only a mean of 4.9 and $3.6 \%$ longer (flipper $34.1 \pm 1.3 \mathrm{~mm}, N=34$ and $32.5 \pm 1.4 \mathrm{~mm}$, $N=23$, respectively and bill $14.3 \pm 0.6 \mathrm{~mm}, N=34$ and $13.8 \pm 0.6 \mathrm{~mm}, N=23$, respectively, Table $3 \mathrm{a}$ ).

Within all the experimental nests, hatching mass for A-chicks was affected by the presence of a sibling, with a mean mass of $61.6 \pm 8.4 \mathrm{~g}(N=20)$ for A-chicks with a sibling at hatching compared to $76.1 \pm 17.4 \mathrm{~g}(N=19)$ for A-chicks without $(U=88.0, P=0.004)$. However, this was not the case for B-chicks $(U=177.0, P=0.262)$. Even when they were alone in the nest, just hatched A-chicks were significantly lighter than B-chicks ( $U=160.5$, $P=0.005)$. The length of the flipper and bill at hatching were not significantly affected by the presence of a sibling (flipper $U=103.55, P=0.066$ for A-chicks and $U=253.0$, $P=0.857$ for B-chicks, bill $U=117.5, P=0.165$ for A-chicks and $U=165.5, P=0.051$ for B-chicks).

\section{Chick survival and growth}

For hatched chicks within AB-nests, the mean survival rate to the end of the brood period was significantly higher for B-chicks ( $80 \%$ of 39 chicks) than for A-chicks (19\% of 32, $U=245.0, P<0.001)$, and did not differ between chicks in early- and late-nests and between sub-colonies $(U=598.5$, $P=0.704$ and $U=620.0, P=0.926$, respectively). Within all experimental nests, the survival rate for A-chicks was affected by the presence of a sibling during the first days after hatching, with a survival rate of $11 \%$ for the 28 A-chicks with a sibling compared to $85 \%$ for the 20 A-chicks without sibling $(U=488.0, P<0.001$, Fig. 1$)$. The survival of the B-chick was not affected by whether it had a sibling or not $(U=394.0, P=0.674$, Fig. 1$)$. Therefore, A- and B-chicks in single chick nests had equal survival rates to the end of the brood period $(U=279.5, P=0.754)$.

Within most experimental nests, only one chick survived beyond the early brood period (Fig. 1). Therefore it was not possible to test the effect on growth of the sibling and we pooled the data from the experimental nests all-together for the following analyses. Sixty-six chicks remaining in all experimental nests were brooded for a mean of $23.0 \pm 2.7$ days old. The brood duration did not differ

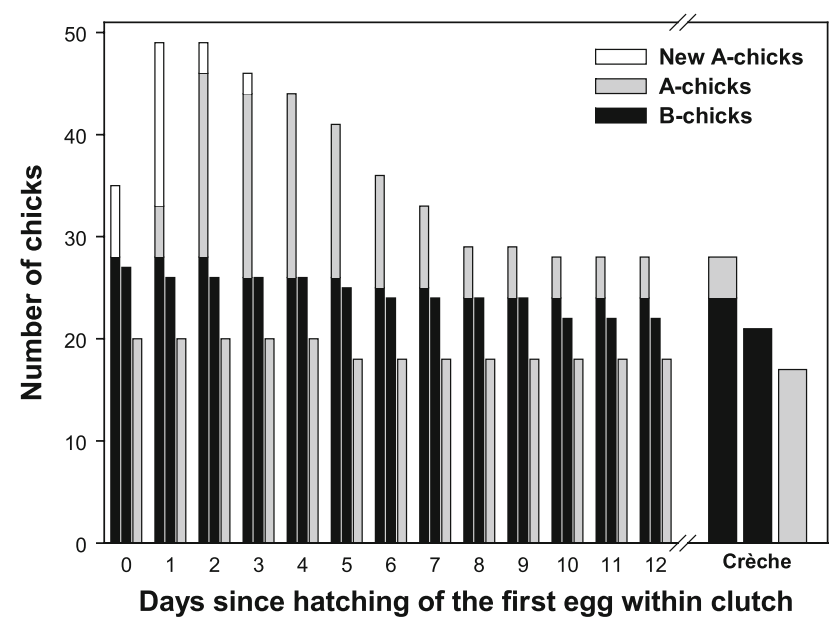

Fig. 1 Number of A- and B-chicks according to day since the hatching of the first chick within the clutch in experimental nests (A-, B- and AB-nests pooled all together). Left bar A- and B-chicks with a sibling at their hatching date. Middle bar B-chicks without sibling at their hatching date. Right bar A-chicks without sibling at their hatching date. A-chicks with a B-sibling are represented in open bars for the day when they hatched and in grey bar afterwards in order to highlight the high mortality early in the brood period

between A- and B-chicks, between early- and late-nests and between sub-colonies (Table $3 b$ ).

Maximum chick body mass was attained at around 50 days before it declined, chick flipper length reached an asymptote at around 35 days, whilst the bill length continued to increase with chick age (Fig. 2). The rate of body mass, flipper length and bill length growth was approximately linear for chicks aged between 5 and 30 days $\left(R^{2}=0.997 \pm 0.003, R^{2}=0.995 \pm 0.006\right.$ and $R^{2}=0.979 \pm$ 0.030 , respectively, $N=64)$. The daily growth rate during this period was not significantly different between A- and B-chicks, between early- and late-nests and between subcolonies (Table 3b).

Manipulation and visitation impacts

There was no significant difference in the rate of decline during the incubation and hatching period of the number of occupied AB- and control-nests in O- and S-colonies combined compared to occupied BS-nests $\left(F_{2,3}=0.823\right.$, $P=0.519$, Fig. 3).

The mean hatching success and the percentage of chicks that survived to 18 days did not differ between control- and AB-nests $(U=1402.0, P=0.381 ; U=1363.0, P=0.196$, respectively). At the age of 18 days, chicks in control-nests had significantly longer flippers than chicks in AB-nests ( $U=628.0, P=0.027$ ) but their body mass and body condition index were not significantly different $(U=758.0$, $P=0.297 ; U=874.0, P=1.000$, respectively). 


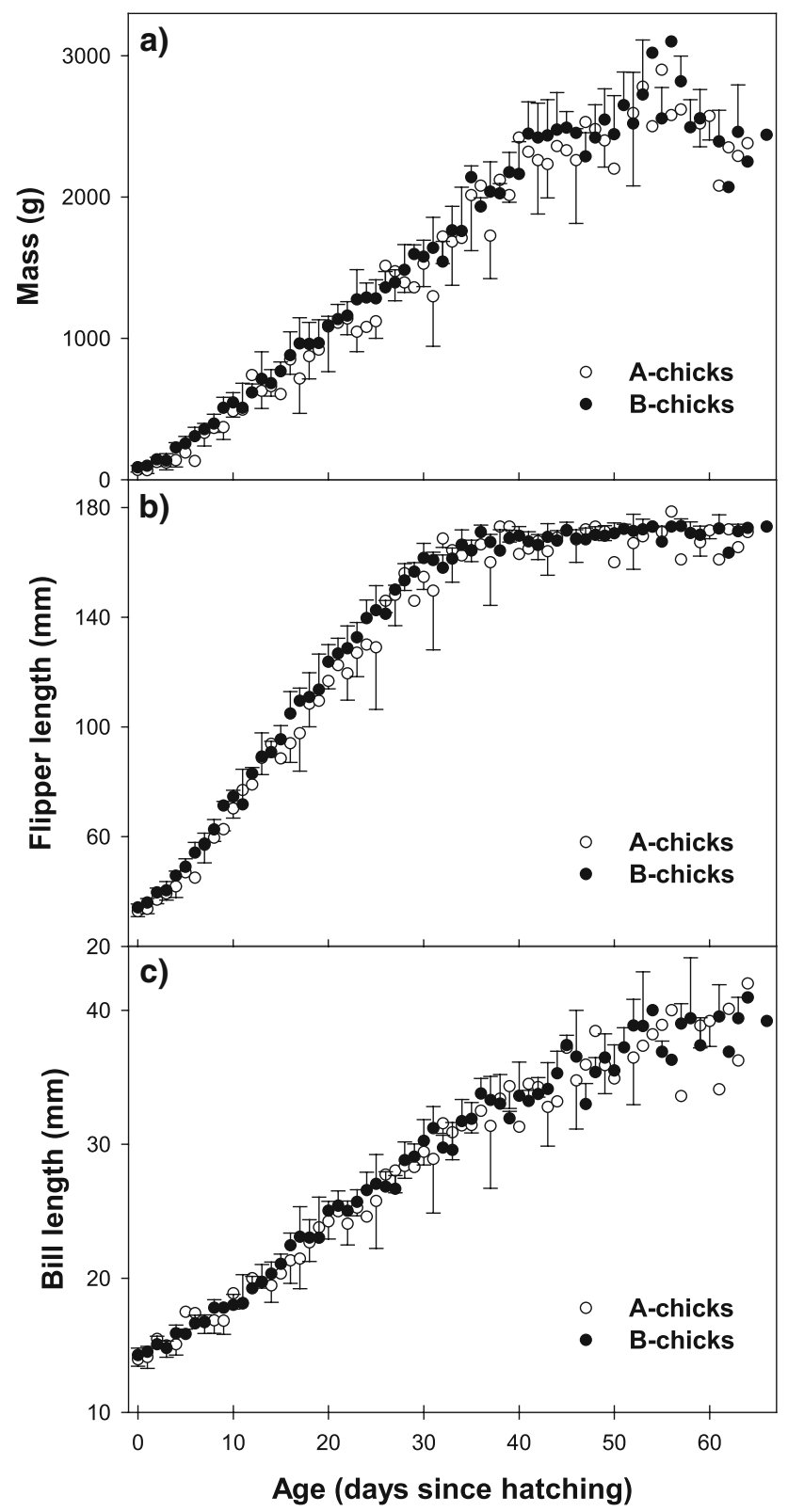

Fig. 2 Change in (a) body mass, (b) flipper length and (c) bill length from the hatching to the fledging age for A-chicks $(N=242$ measurements) and B-chicks ( $N=494$ measurements) from A-, B- and ABnests. Means \pm SD for ages with more than two measurements and only means for ages with one or two measurements

The breeding success for AB-nests was 0.69 chicks per nest ( 37 chicks for 54 nests) with only one pair raising two chicks until fledging, with an additional two nests within the 60 control-nests with two chicks aged 18 days. Although the control-chicks were not marked, it was possible to monitor them for the full rearing period because the daily meeting between feeding parent and chick always occurred at the nest site, which was marked. Thus, the observed two-chick success rate in 114 observed nests was $2.6 \%$.

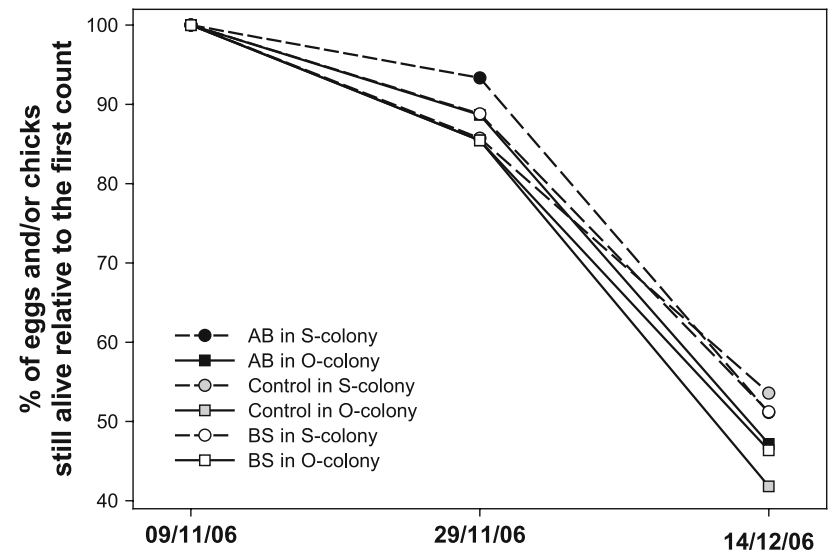

Fig. 3 The decline in the number of occupied AB- and control-nests in $\mathrm{O}$ - and $\mathrm{S}$-colonies compared to occupied BS-nests between the three counts made during the incubation and hatching period as expressed as a percentage of the first initial count

\section{Discussion}

Breeding characteristics of the chrysocome species

Southern rockhopper penguins breeding at New Island appear to have not altered during the study period 1980 2006, with a 16-day long laying period (Strange 1982; Lamey 1990, 1993; St. Clair 1996; St. Clair and St. Clair 1996; this study). This rigid laying behaviour has also been observed for conspecifics breeding elsewhere (Marchant and Higgins 1990; Williams 1995). It is highly likely that this synchrony is the reason for the lack of any significant differences between pairs that laid early or late in the breeding season in the dimensions of eggs, hatching success, chick growth rates and chick survival to the end of the brood and crèche periods.

It has been suggested that dense vegetation confers an advantage to breeding rockhopper penguins, particularly against aerial predation (Williams 1980b; St. Clair and St. Clair 1996). Our study supported previous research on New Island (Matias 2005) that the breeding success of the southern rockhopper penguin is not affected by the habitat of the sub-colony (that is, the amount of vegetation and rock cover). However, we suggest that the amount of tussac grass in the semi-open area (S-colony) was probably not dense enough to confer effective protection against the aerial predators found on New Island, including the brown skua Catharacta antarticus and striated caracara Phalcoboenus australis. The influence of habitat on breeding success of crested penguins requires further investigation and we suggest that open, rocky areas may also confer some benefits, as we observed that fewer eggs were lost by accidental displacement in O-colony than S-colony, perhaps because 
the rocks provide a protective barrier between nests (M. Poisbleau and L. Demongin, personal observation).

\section{Breeding success and visitation impacts}

As Hull and Wilson (1996) demonstrated for the southern rockhopper penguin breeding on Macquarie Island, we also found no significant differences in hatching success, chick growth rates, chick survival to the end of the brood period and fledging rates between pairs that were disturbed and caught regularly, pairs that were disturbed but adults and chicks were not captured and pairs that bred in areas that were only visited for three nest counts. Whilst the flipper length of chicks at 18 days of age was slightly different between studied and control-chicks, as we did not determine chick gender in this study, the effect of gender on growth cannot be excluded as a possible explanatory factor. However, no studies have considered the effects of handling on the subsequent breeding attempts of males and females, nor on immature or non-breeding birds, which can be seen in the colony throughout the breeding season. It is an area for further study but can only be carried out at long-term study sites where penguins are individually marked and monitored annually.

New consideration on the intrinsic capacity of the A-egg

It is well documented that the rockhopper penguin lays two eggs, with the first egg being smaller and lighter than the second, which is laid up to four days later (Williams 1995). Although laid later, the B-egg usually hatches first and this has been suggested to occur due to differences in egg composition resulting from the laying order or date (Burger and Williams 1979; Brown 1988; St. Clair 1996) and/or subsequent differential parental incubation behaviour towards the A-egg or B-egg, which results in a different incubation temperature and therefore embryonic metabolism of the egg (Burger and Williams 1979). In our study, the incubation duration was similar when A- and B-eggs were incubated singularly, suggesting that the parental effect hypothesis is favoured. This hypothesis is further supported by the result in our study that the presence of a sibling significantly affects the hatching success and hatching mass of the A-egg but not the B-egg. We suggest that the optimal incubating position is occupied by larger and heavier B-egg.

In most crested penguin species, it has been suggested that the optimal position is in the posterior part of the brood patch because there it is less exposed to predation, better insulated and is less likely to be actively ejected by the parent or first-hatched chick (Gwynn 1953; St. Clair 1996, St. Clair and St. Clair 1996). Of the two-egg clutches monitored in our study, both eggs hatched at $53 \%$ of the nests with at least one hatched egg and A- and B-eggs had an equal rate of hatching, but A-chicks in AB-nests had a lower survival rate to the end of the brood period. However, when alone, A-chicks had a similar rate of survival to the end of the brood period, a similar growth rate and a similar age at the end of the brood period as B-chicks. Both the larger size at hatching and the one day earlier start made by B-chicks most likely play the most important direct or indirect competitive role in the higher A-chick mortality within AB-nests.

This study demonstrated for the first time that the A-egg produced by the southern rockhopper penguin has, when alone, theoretically the same intrinsic potential to lead to a fledged chick as the B-egg. The A-egg is not less viable as has been suggested by Williams (1981) and St. Clair and St. Clair (1996). Therefore, when conditions are optimal (i.e. low predation and sufficient food resources), the southern rockhopper penguin can produce two chicks. This is reflected in the breeding successes reported for various colonies across the Falkland Islands since 1993 being on average between 0.54 and 0.95 (range $0.45-1.28$ ) chicks per breeding pair (Huin 2005) compared to less than 0.61 chicks per breeding pair for E. moseleyi and E. c. filholi breeding in the Indian Ocean and Pacific Ocean (Williams 1995).

Although our study has demonstrated that the southern rockhopper penguin in the Falkland Islands has the potential for much higher breeding success than previously thought (i.e. for two chicks per breeding pair), this is not reflected in the long term population trend of the species, which has been in a severe decline since the 1930s (Pütz et al. 2003a). New information provided by long-term monitoring of individual penguins, including juveniles and adults, in relation to at-sea conditions is crucial in order to devise an appropriate Species Action Plan.

Acknowledgments We are grateful to the New Island Conservation Trust for permission to work on the island and for providing all accommodation, food and internal travel costs. We wish to thank Maria and Georgina Strange, Dan Birch, Riek van Noordwijk, Miguel Lecoq and Juan F. Masello for their support and advice during the field season. Charles-André Bost, Léopold Denonfoux, Olivier Chastel and Paulo Catry provided essential advice on methodologies. Thanks also to Falkland Conservation and British Antarctic Survey for their logistic help. The manuscript benefited greatly from critical comments by two anonymous referees. This study was funded by a grant provided by the Deutsche Forschungsgemeinschaft DFG (Qu 148/1-ff) and conducted under a research licence granted by the Environmental Planning Department of the Falkland Islands Government.

Open Access This article is distributed under the terms of the Creative Commons Attribution Noncommercial License which permits any noncommercial use, distribution, and reproduction in any medium, provided the original author(s) and source are credited.

\section{References}

Amat JA, Viñuela J, Ferrer M (1993) Sexing chinstrap penguins (Pygoscelis antarctica) by morphological measurements. Colonial Waterbirds 16:213-215 
Banks J, Van Buren A, Cherel Y, Whitfield JB (2006) Genetic evidence for three species of rockhopper penguins, Eudyptes chrysocome. Polar Biol 30:61-67

Boersma PD, Stokes DL, Strange I (2002) Applying ecology to conservation: tracking breeding penguins at New Island South Reserve, Falkland Islands. Aquat Conserv Mar Freshw Ecosyst 12:63-74

Brown CR (1988) Egg temperatures and embryonic metabolism of A- and B-eggs of macaroni and rockhopper penguins. S Afr J Zool 23:166-172

Burger AE, Williams AJ (1979) Egg temperatures of the rockhopper penguin and some other penguins. Auk 96:100-105

Clausen AP, Pütz K (2002) Recent trends in diet composition and productivity of gentoo, magellanic and rockhopper penguins in the Falkland Islands. Aquat Conserv Mar Freshw Ecosyst 12:51-61

Gwynn AM (1953) The egg-laying and incubation periods of rockhopper, macaroni and gentoo penguins. ANARE Rep Ser B 1:1-29

Huin N (2005) Falkland Island Seabird Monitoring Programme Annual Report 2003/2004 and 2004/05. Falkland Conservation, Stanley

Huin N (2007) Falkland Islands penguin census 2005/06. no. Falklands Conservation, Stanley

Hull CL, Hindell M, le Mar K, Scofield P, Wilson J, Lea M-A (2004) The breeding biology and factors affecting reproductive success in rockhopper penguins Eudyptes chrysocome at Macquarie Island. Polar Biol 27:711-720

Hull CL, Wilson J (1996) The effect of investigators on the breeding success of royal, Eudyptes schlegeli, and rockhopper penguins, E. chrysocome, at Macquarie Island. Polar Biol 16:335-337

Jouventin P, Cuthbert RJ, Ottvall R (2006) Genetic isolation and divergence in sexual traits: evidence for the northern rockhopper penguin Eudyptes moseleyi being a sibling species. Mol Ecol 15:3413-3423

Lamey TC (1990) Hatch asynchrony and brood reduction in penguins. In: Davis LS, Darby JT (eds) Penguin biology. Academic Press, San Diego, pp 399-416

Lamey TC (1993) Territorial aggression, timing of egg loss, and eggsize differences in rockhopper penguins, Eudyptes c. chrysocome, on New Island, Falkland Islands. Oikos 66:293-297

Marchant S, Higgins PJ (1990) Handbook of Australian, New Zealand and Antarctic birds, vol 1. Ratites to ducks. Part A ratites to petrels. Oxford University Press, Melbourne

Matias R (2005) Rockhopper penguins and some of its predators on New Island, Falkland Islands. Contributions to the knowledge of a globally threatened species. University of Lisbon (Portugal) Biology Degree thesis
Pütz K, Clausen AP, Huin N, Croxall JP (2003a) Re-evaluation of historical rockhopper penguin population data in the Falkland Islands. Waterbirds 26:169-175

Pütz K, Ingham RJ, Smith JG, Croxall JP (2001) Population trends, breeding success and diet composition of gentoo Pygoscelis papua, magellanic Spheniscus magellanicus and rockhopper Eudyptes chrysocome penguins in the Falkland Islands. Polar Biol 24:793-807

Pütz K, Ingham RJ, Smith JG, Lüthi BH (2002) Winter dispersal of rockhopper penguins Eudyptes chrysocome from the Falkland Islands and its implications for conservation. Mar Ecol Prog Ser 240:273-284

Pütz K, Raya Rey A, Schiavini A, Clausen AP, Lüthi BH (2006) Winter migration of rockhopper penguins (Eudyptes c. chrysocome) breeding in the Southwest Atlantic: is utilisation of different foraging areas reflected in opposing population trends? Polar Biol 29:735-744

Pütz K, Smith JG, Ingham RJ, Lüthi BH (2003b) Satellite tracking of male rockhopper penguins Eudyptes chrysocome during the incubation period at the Falkland Islands. J Avian Biol 34:139-144

Robinson S, Chiaradia A, Hindell MA (2005) The effect of body condition on the timing and success of breeding in little penguins Eudyptula minor. Ibis 147:483-489

St. Clair CC (1996) Multiple mechanisms of reversed hatching asynchrony in rockhopper penguins. J Anim Ecol 65:485-494

St. Clair CC (1998) What is the function of first eggs in crested penguins? Auk 115:478-482

St. Clair CC, St. Clair RC (1996) Causes and consequences of egg loss in rockhopper penguins, Eudyptes chrysocome. Oikos 77:459466

Stonehouse B (1966) Egg volumes from linear dimensions. Emu 65:227-228

Strange IJ (1982) Breeding ecology of the rockhopper penguin (Eudyptes crestatus) in the Falkland Islands. Gerfaut 72:137-188

Warham J (1975) The crested penguins. In: Stonehouse B (ed) The biology of penguins. The Macmillan Press, London, pp 189-269

Williams AJ (1980a) Offspring reduction in macaroni and rockhopper penguins. Auk 97:754-759

Williams AJ (1980b) Rockhopper penguins Eudyptes chrysocome at Gough Island. Bull B O C 100:208-212

Williams AJ (1981) The clutch size of macaroni and rockhopper penguins. Emu 81:87-90

Williams TD (1995) The penguins. Oxford University Press, Oxford 